\title{
Primeiro Herói: Plataforma de Game-based Learning e Sistema de Recomendação de Atividades Integradoras para engajamento dos Pais na Educação dos Filhos
}

\author{
Érica Stamato $^{1}$, Reginaldo Gotardo ${ }^{1}$, Paulo César de Carvalho Dias ${ }^{1}$, Seiji Isotani ${ }^{2}$, \\ Maria Neli Volpini ${ }^{1}$ \\ ${ }^{1}$ Cross Reality Sistemas \\ Ribeirão Preto, S.P. \\ ${ }^{2}$ ICMC - Universidade de São Paulo \\ São Carlos, S.P. \\ erica.stamato@gmail.com, reggotardo@gmail.com, pccdias@gmail.com, \\ sisotani@icmc.usp.br, nelivolpini@gmail.com
}

\begin{abstract}
Resumo. Este artigo apresenta a Plataforma Primeiro Herói que reúne um jogo educacional mobile para crianças de 5 a 10 anos, uma aplicação web (e e-mail) para pais ou responsáveis receberam detalhes sobre a utilização dos filhos, um sistema de recomendação que envia sugestões de atividades integradoras, fora do ambiente digital, entre pais e filhos. Todos estes recursos estão envoltos num amplo processo de gamificação e mapeamento de competências em letramento matemático.
\end{abstract}

\section{Cenário de Uso}

Entende-se que a linguagem matemática, bem como o desenvolvimento do pensamento lógico-matemático em todos os níveis do processo de desenvolvimento da inteligência infanto-juvenil, constitui a base para a estruturação do pensamento hipotético-dedutivo. Este pensamento é fundamento central para a aprendizagem das outras áreas que compõem o currículo nacional da Educação Básica, do Ensino Médio, Técnico e Universitário, bem como do ingresso no mercado de trabalho e no campo da pesquisa científica, além de viabilizar a vivência da autonomia moral em comunidade.

Pais ou responsáveis são importantes referências para a formação sócio afetiva do ser humano. Buscando uma integração entre as novas tecnologias e a afetividade familiar, a empresa Cross Reality elaborou jogos a partir dos princípios de Game-based Learning e Competence-based Learning, unindo o virtual e o real. O nome do aplicativo é Primeiro Herói, referência à importante etapa do imaginário infantil que vê no seu cuidador um Herói. Quando a criança percebe a sua individualidade e dependência do adulto, tende a projetá-lo como alguém poderoso no sentido de protegê-la das ameaças reais e imaginárias.

O conteúdo dos jogos foi desenvolvido com base nos PCNs de Matemática para o Ensino Fundamental I. A faixa etária para utilização é entre 5 e 10 anos de idade.

O Aplicativo Primeiro Herói, oferece jogos educativos que envolvem pais e filhos. Seu uso é gratuito e está disponível para tablets e smartphones. O acesso inicial é feito através de nosso site: www.primeiroheroi.com.br 
CBIE-LACLO 2015

Anais dos Workshops do IV Congresso Brasileiro de Informática na Educação (CBIE 2015)

O jogo está disponível no Google Play em:

- $\quad$ https://play.google.com/store/apps/details?id=com.CrossReality.Primeiro_Heroi $\underline{\& h l=p t ~ B R}$

É possível baixa-lo e jogar no modo de demonstração. Com o cadastro, que é gratuito, os pais ou responsáveis poderão gerar até 4 logins de seus mini-heróis. Com isto, as crianças terão acesso ao jogo completo.

Os pais ou responsáveis exercem importantes funções no processo educacional, estimulando e valorizando as conquistas da criança.

Primeiro Herói não é apenas um jogo ou aplicativo, é um conceito que se vale do jogo, do aplicativo e da plataforma de acompanhamento para os pais e geração de recomendações personalizadas de interação. A abordagem da empresa Cross Reality vem de anos de pesquisas de sua equipe pedagógica e busca na tecnologia uma nova forma para estimular a interação familiar e o desenvolvimento cognitivo infantil.

O game possui avatares para os adultos e para as crianças, seis fases com 48 desafios de lógica matemática para jogadores entre 5 e 10 anos.

Os jogos foram fornecidos pela Educacross ${ }^{1}$, uma completa Plataforma para apoio ao ensino de matemática que é usada nas escolas e também foi criada pela empresa que desenvolveu o Primeiro Herói, a Cross Reality.

\section{Desenvolvimento}

O estado da arte, no que tange à necessidade de ratificar a importância e benefícios das denominadas novas tecnologias de informação e comunicação (TIC) no âmbito escolar, são inegáveis e abundantes destacando-se ainda as contribuições de Garonce e Santos (2012). Citando Castells (2007), esclarecem que vivemos hoje a "cultura da virtualidade real" e segundo suas investigações a inserção da videoconferência pela internet, denominada web conferência, no ambiente educacional, tem causado impactos provocados por essa tecnologia na relação educativa, na forma de se ensinar e na forma de se aprender, focando, por exemplo, as alterações dos papéis docentes neste contexto.

No contexto de uma proposta de ensino e aprendizagem que objetiva a autonomia intelectual através da interação do sujeito cognoscente com o objeto de conhecimento, abstraído da ferramenta "computador", Ferreira e Duarte (2012) encontram em suas pesquisas, quanto às concepções de ensino e aprendizagem no campo da literatura brasileira de informática educativa, uma certa hegemonia das pedagogias do aprender a aprender, ancoradas no construtivismo e construcionismo, além da pedagogia de projetos e de competências.

A plataforma Primeiro Herói nasceu com o intuito de aproximar e engajar os pais no contexto educacional e contempla, como pode ser visto na figura 1 , os recursos lúdicos de jogos educativos, um sistema de acompanhamento na forma de relatórios, e um sistema de recomendações de atividades de integração entre pais e filhos. A próxima versão contemplará ainda os recursos de interação e feedback (para que os pais possam

\footnotetext{
${ }^{1}$ www.educacross.com.br
} 
também participar e interagir) e dicas de especialistas (através dos direcionamentos) para novas atividades pedagógicas. O sistema de recomendação é focado em interações familiares, o sistema de direcionamento será focado em interações pedagógicas.
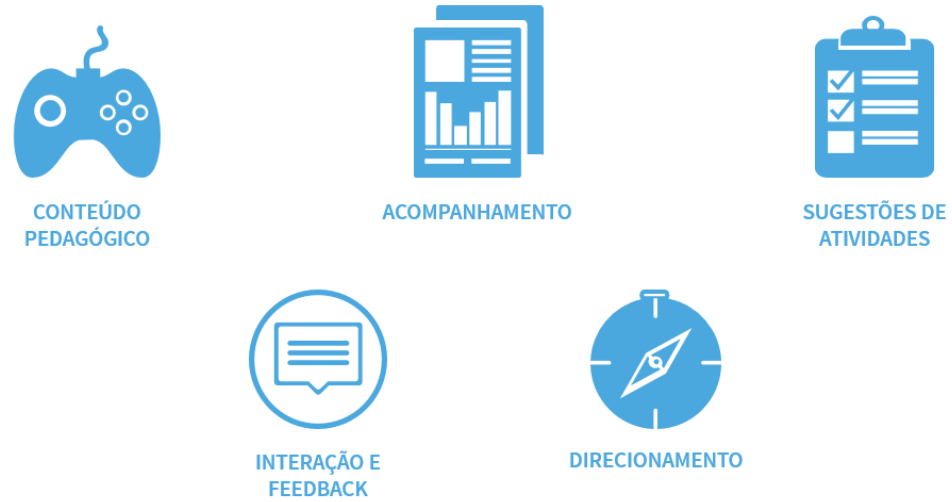

Figura 1. Recursos da Plataforma Primeiro Herói

A Plataforma Primeiro Herói nasceu como um spin-off B2C da Educacross. A Educacross é uma plataforma B2B para escolas que visa auxiliar professores com um sistema complementar para ensino de matemática num processo gamificado.

No final do ano de 2014, ao participar da final do desafio Brasil de Inovação na Educação, a Educacross recebeu importante feedback e, um deles em particular, despertou o interesse da equipe em lançar algo para o mercado B2C.

O projeto foi desenvolvido em 8 fases como pode ser visto, já aproveitando o método, conteúdos e recursos existentes na Educacross. A plataforma Educacross possui mais de 350 jogos de letramento matemático para o Ensino Fundamental I.

A) Análise Pedagógica: Análise dos conteúdos pedagógicos da Matemática do Ensino Fundamental. Nessa etapa foram revisitados conceitos epistemológicos (propostos pelos estudos de Piaget e Vygotsky) para criação de atividades e jogos e a transferência destes para o ambiente digital, bem como entrevista com professores da rede pública para a identificação de necessidades e ajustes pertinentes, respeitando-se as características do pensamento lógico-matemático das faixas etárias, atreladas às questões da didática da matemática.

B) Observação, registro e análise da interação da criança com as atividades: foram realizados testes dos jogos da Educacross em escolas parceiras, observando as crianças na utilização dos jogos da plataforma.

C) Registro em planilhas com descritores avaliativos, envolvendo crianças de todas as séries do Ensino Fundamental I (por amostragem), análises avaliativas posteriores.

D) Identificação das Métricas e Indicadores relevantes para apresentação na Plataforma. Foram analisados os conceitos-chave que envolvem os eixos dos conteúdos elencados. Também foram definidas e criadas as métricas e os 
indicadores que devem são extraídos dos jogos que são disponibilizados na plataforma.

E) Modelagem da Base de Dados: foi criado o modelo de dados e a implementação inicial para armazenamento dos dados importantes das métricas para acompanhamento de desempenho das crianças.

F) Desenvolvimento do sistema de recomendação de atividades: o sistema de recomendação usa a abordagem demográfica, personalizando as recomendações de acordo com informações dos cadastros dos pais e das crianças.

G) Aplicação dos Protótipos e Avaliação: Foi lançado um teste beta com um grupo de pessoas e com registro de interações. As melhorias propostas foram realizadas e, por fim, o produto final foi lançado dia 15 de abril de 2015.

H) Acompanhamento sistemático do plano pedagógico e orientações didáticas para garantir que o método desenvolvido seja devidamente aplicado nos conceitos dos jogos relacionados ao PCN: Essa fase acompanhou todo o desenvolvimento do projeto visando auxiliar o gerenciamento e adequação do mesmo em relação aos resultados obtidos durante as vivências das crianças e testes dos pais.

\section{Apresentação do software}

Com a falta de tempo dos pais e a progressiva imersão dos jovens no mundo virtual, preocupa-nos o crescente afastamento nas relações familiares. Nossa proposta é unir a tecnologia, que já ocupa os espaços contemporâneos, com pequenas ações cotidianas que ajudam a fortalecer os laços familiares. A participação dos pais acontece no cadastro inicial de seus mini-heróis e na liberação dos itens de avatar. Como visto na figura 2, o avatar do pai, mãe ou responsável está sempre presente no jogo, lembrando a criança da sua referência, seu herói ou heroína.

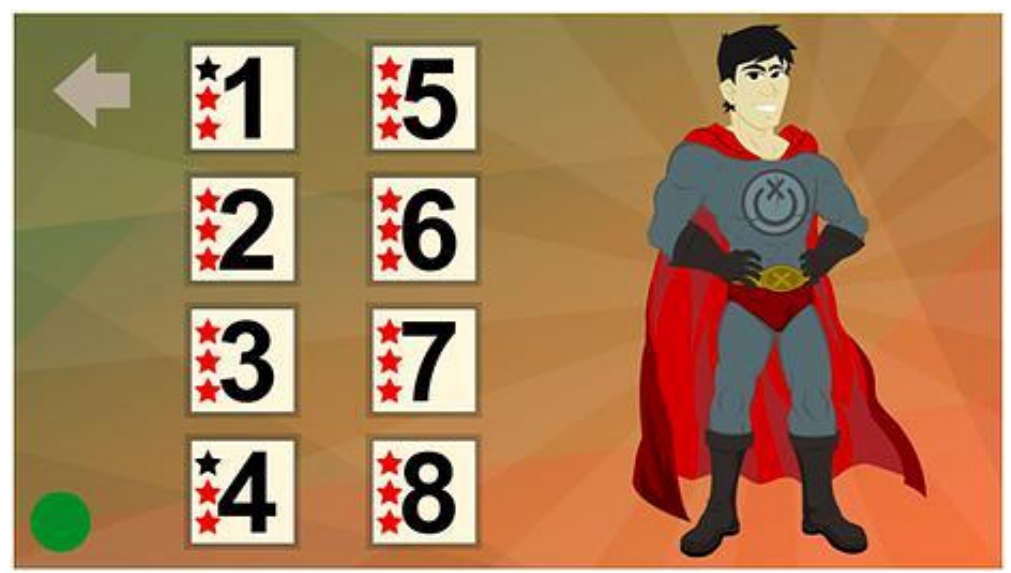

Figura 2. A referência do Herói/Heroína para a criança

A participação de pais e filhos nas etapas do game acontece de forma lúdica e simples. O sistema de gameficação desenvolvido envolve uma mecânica evolutiva e, a cada etapa vencida, a criança ganha um novo acessório para a sua personificação de herói. 


\section{CBIE-LACLO 2015}

Anais dos Workshops do IV Congresso Brasileiro de Informática na Educação (CBIE 2015)

Esse acessório será disponibilizado pelo responsável (pai, mãe, tios, avós) que receberá um e-mail com relato do desempenho da criança, das atividades desenvolvidas naquela etapa, e sugestões de atividades simples, porém significativas para serem vivenciadas entre eles (figura 3 ).
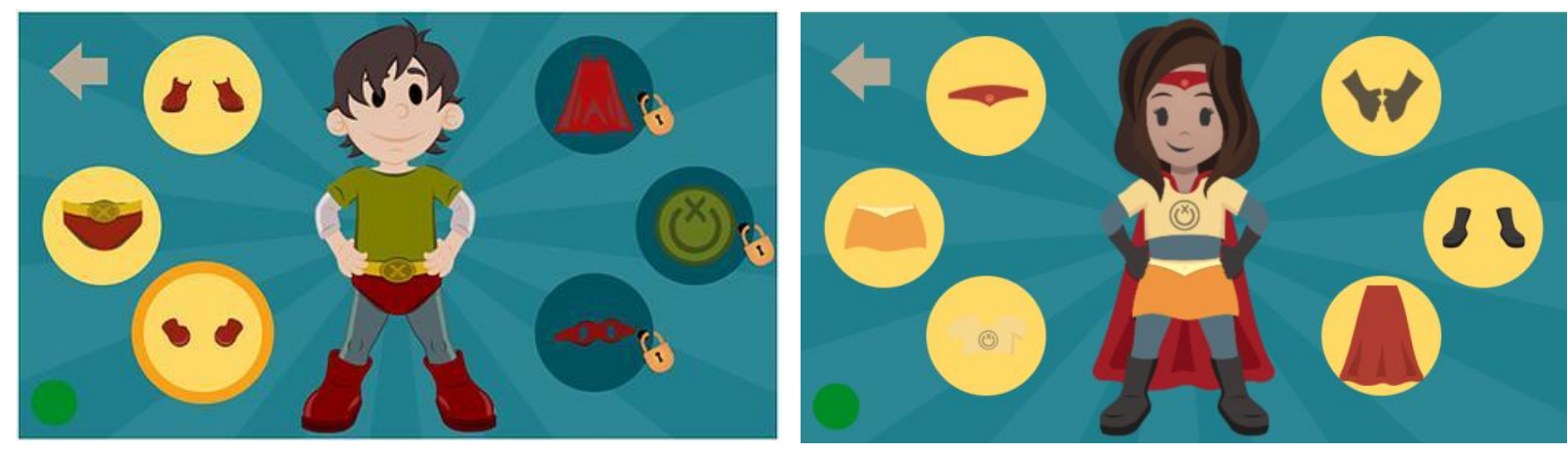

Figura 3. A personificação do Herói pela criança

Para a criança, a interação se dá através dos diversos desafios de lógica matemática (figura 4) e da gamificação com a construção do personagem, Mini-Herói, que vai acontecendo gradativamente, a cada etapa vencida.

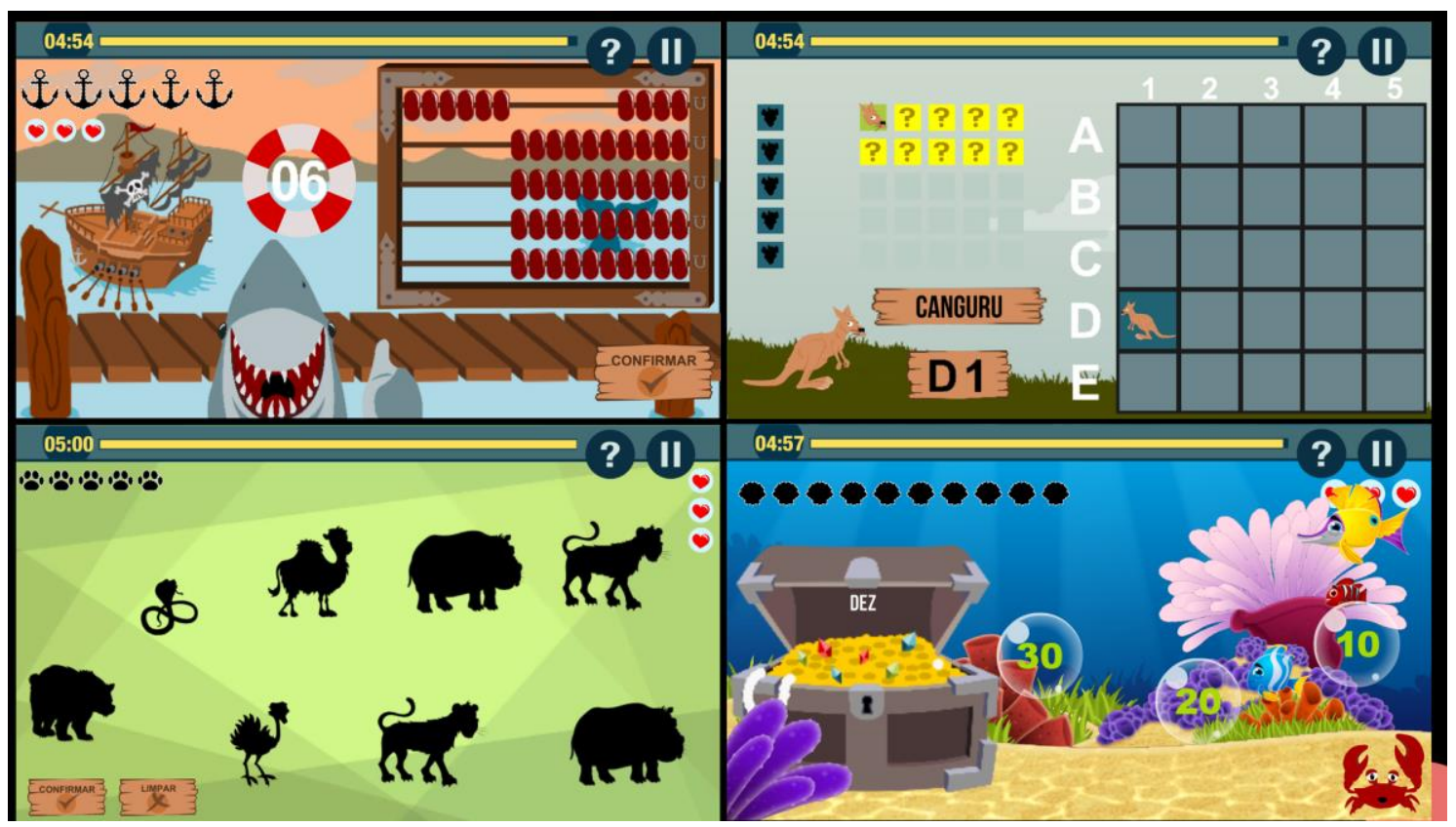

Figura 4. Desafios lógicos-matemáticos na forma de jogos lúdicos

Já para o responsável, a interação acontece através de notificações a cada etapa concluída, que indicam as conquistas da criança e não leva mais que dois minutos para a leitura (figura 5). As habilidades exercitadas, o desempenho alcançado e as sugestões de interação no mundo real são apresentadas de forma concisa e pratica. 


\section{CBIE-LACLO 2015}

Anais dos Workshops do IV Congresso Brasileiro de Informática na Educação (CBIE 2015)

As atividades propostas entre pais e filhos no mundo real tem duração média de 10 minutos, como, por exemplo:

- Combine com seu mini-herói um sinal, ou um cumprimento só de vocês.

- Vamos contar história? Relate ao seu mini-herói como foi o dia do nascimento dele.

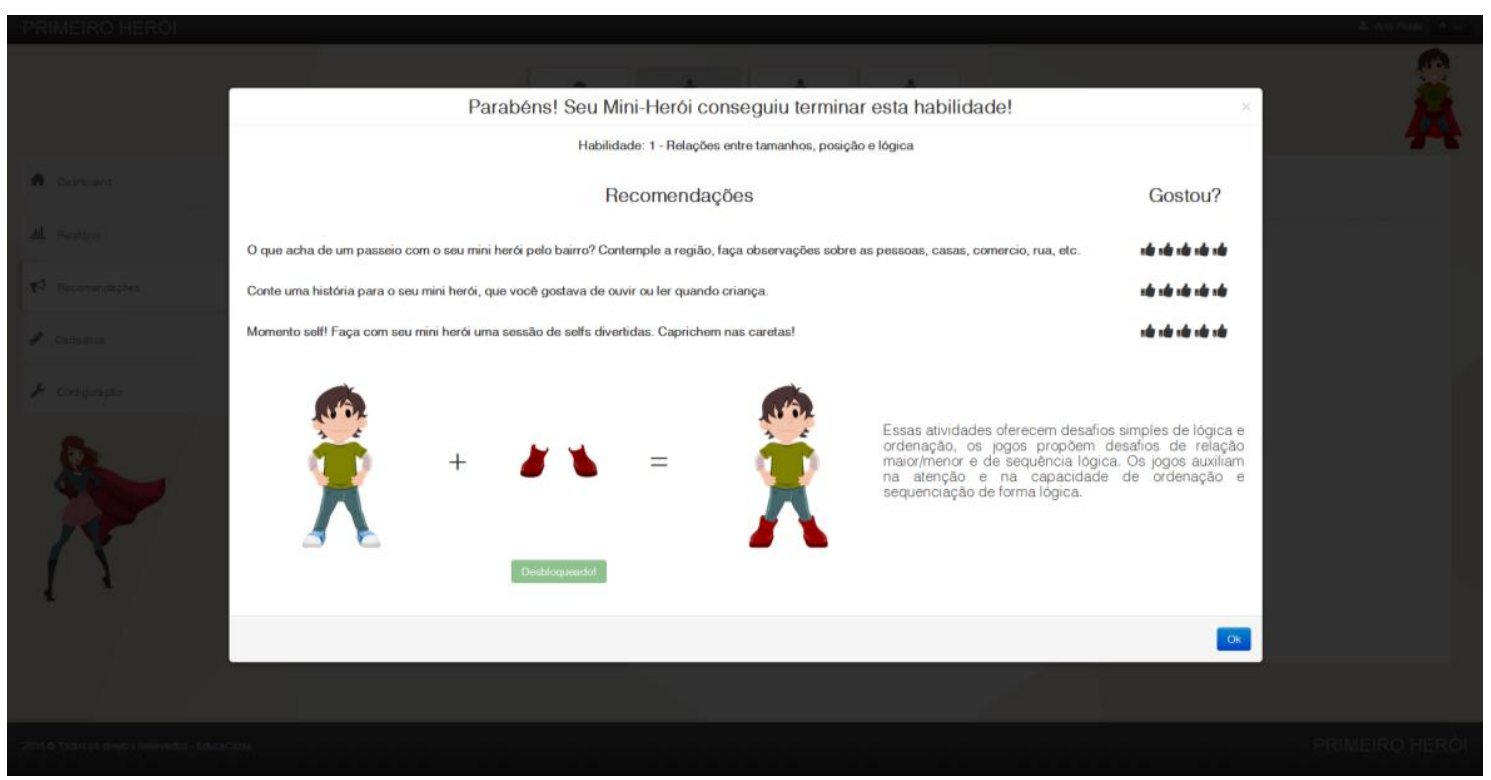

Figura 5. Recomendação feita para os pais ou responsáveis

Essa interação é feita por um sistema de recomendação de atividades especialmente desenvolvido para o game. Nenhum outro jogo digital explora as relações humanas dessa maneira e essa é nossa maior proposta.

Além das recomendações no site os pais recebem também um relatório demonstrativo por e-mail a cada vez que um de seus mini-heróis completa um conjunto de tarefas e conquista um item do avatar.

A Plataforma Primeiro Herói permite acompanhar cada um dos mini-heróis de um responsável através de relatórios simples e objetivos logo na tela inicial de dashboard (figura 6). 


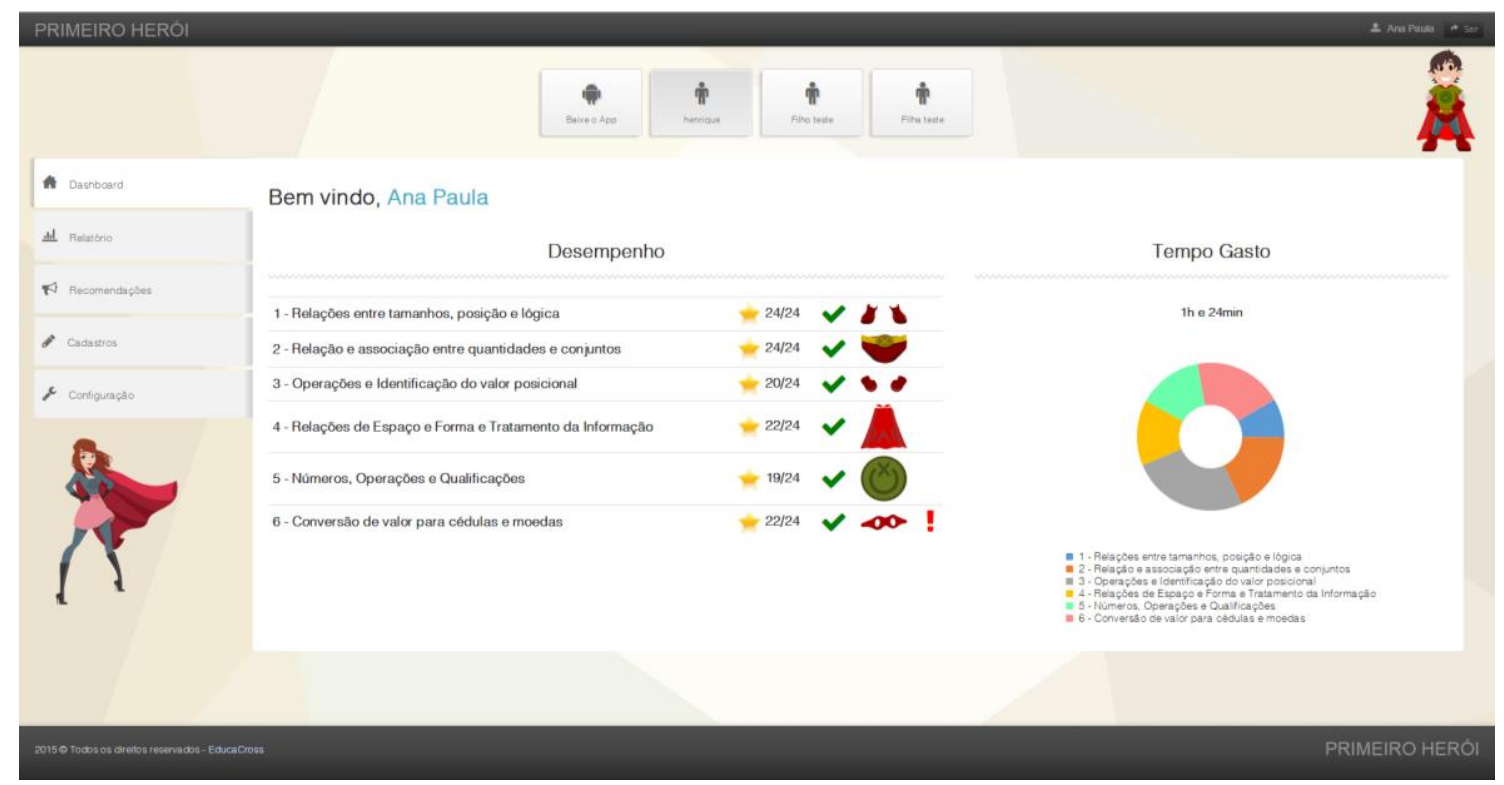

Figura 6. Relatório de acompanhamento geral (dashboard)

Também são dispostos relatórios mais detalhados e informações básicos do conteúdo do jogo (figura 7) para que os pais possam entender o que seus pequenos estão trabalhando dentro dos jogos.
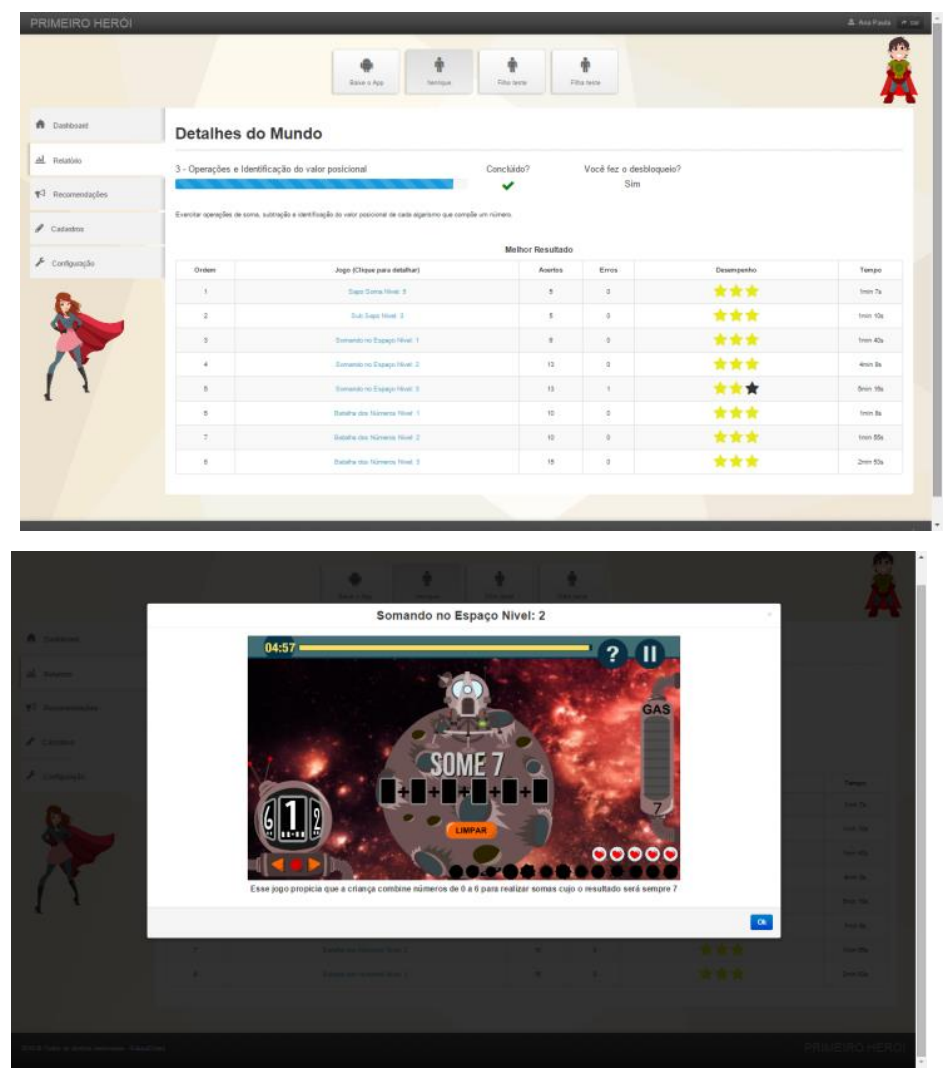

Figura 7. Relatórios detalhados e informações para os pais. 


\section{Considerações Finais}

A Plataforma Primeiro Herói já tem mais de 200 usuários. O modelo de monetização é freemium. Por hora foi lançada gratuitamente para cadastro de até 4 mini-herói por responsável. Em breve lançaremos recursos extras que poderão ser contratados pelos pais, caso desejem.

Os principais resultados obtidos foram o engajamento de pais e crianças através de jogos especialmente preparados para o letramento matemático. Mesmo possuindo conteúdos pedagógicos, o design de experiência do usuário visa ocultar isto, tornando o jogo mais atrativo e mais próximo de um jogo de entretenimento.

A empresa Cross Reality está inserida na incubadora de empresas com base em tecnologia Supera, em Ribeirão Preto (SP). Atua como desenvolvedora de soluções educacionais inovadoras, formada por uma equipe com profissionais de diversas áreas. Entre seus projetos está disponível no mercado educacional a plataforma Educacross, que fornece para escolas um conjunto de ferramentas baseadas em jogos, inserindo a tecnologia no ambiente e nos processos educacionais. É uma solução que envolve professores, alunos, pais e gestores educacionais em mais de 350 jogos digitais com recursos contemporâneos e atrativos da gamificação.

\section{Referências}

CASTELLS, M. A Sociedade em Rede - A era da informação: economia, sociedade e cultura. São Paulo: Paz e Terra, 2007.

FERREIRA, Benedito de Jesus Pinheiro; DUARTE, Newton II Educação e Sociedade. vol.33 no.121 Campinas out./dez. 2012 http://dx.doi.org/10.1590/S010173302012000400006.

GARONCE, Francisco; SANTOS, Gilberto Lacerda II Educação e Sociedade. vol.33 n.121 Campinas out./dez. 2012 http://dx.doi.org/10.1590/S010173302012000400005 . 